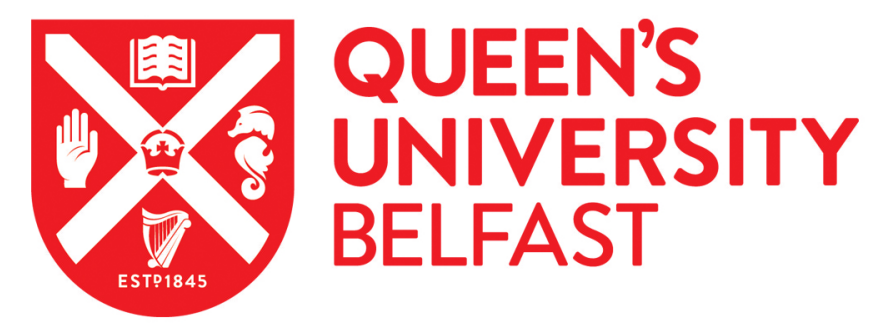

\title{
Training in Multiple Breath Washout testing for respiratory physiotherapists
}

O'Neill, K., Elborn, J. S., Tunney, M. M., O'Neill, P., Rowan, S., Martin, S., \& Bradley, J. M. (2018). Training in Multiple Breath Washout testing for respiratory physiotherapists. Physiotherapy, 104(1), 61-66.

https://doi.org/10.1016/j.physio.2017.04.003

\section{Published in:}

Physiotherapy

\section{Document Version:}

Peer reviewed version

\section{Queen's University Belfast - Research Portal:}

Link to publication record in Queen's University Belfast Research Portal

\section{Publisher rights}

Copyright 2017 Elsevier.

This manuscript is distributed under a Creative Commons Attribution-NonCommercial-NoDerivs License

(https://creativecommons.org/licenses/by-nc-nd/4.0/), which permits distribution and reproduction for non-commercial purposes, provided the author and source are cited.

\section{General rights}

Copyright for the publications made accessible via the Queen's University Belfast Research Portal is retained by the author(s) and / or other copyright owners and it is a condition of accessing these publications that users recognise and abide by the legal requirements associated with these rights.

Take down policy

The Research Portal is Queen's institutional repository that provides access to Queen's research output. Every effort has been made to ensure that content in the Research Portal does not infringe any person's rights, or applicable UK laws. If you discover content in the Research Portal that you believe breaches copyright or violates any law, please contact openaccess@qub.ac.uk. 


\section{Debate article}

2 Title: Training in Multiple Breath Washout testing for respiratory physiotherapists

3

4 Authors: Katherine O’Neill ${ }^{1}$, J. Stuart Elborn ${ }^{1}$, Michael M. Tunney ${ }^{2}$, Philip O’Neill ${ }^{3}$, Stephen

$5 \quad$ Rowan $^{4}$, Susan Martin ${ }^{5}$, Judy M. Bradley ${ }^{6}$

6

7 Acknowledgements: Thank you to Dr Alex Horsley for providing training and expertise on the

8 use the modified Innocor ${ }^{\mathrm{TM}}$ device. Thank you to Dr Nick Bell for his permission to use the

9 Simple Washout software. Thank you to Prof Jane Davies, Clare Saunders and Katie Bayfield

10 for their guidance on training programme structure and content.

${ }^{1}$ Centre for Experimental Medicine, Queen’s University Belfast, United Kingdom

${ }^{2}$ School of Pharmacy, Queen’s University Belfast, United Kingdom

${ }^{3}$ Office for Digital Learning, Ulster University, United Kingdom

${ }^{4}$ South Eastern Health and Social Care Trust, United Kingdom

${ }^{5}$ Northern Ireland Clinical Trials Unit, Belfast Health and Social Care Trust, United Kingdom

${ }^{6}$ Northern Ireland Clinical Research Facility, Queen’s University Belfast, United Kingdom

Corresponding author: Katherine O’Neill, Centre for Experimental Medicine, 3rd Floor,

Medical Biology Centre, Lisburn Road, Queen's University Belfast, BT9 7BL. Email:

k.oneill@qub.ac.uk.

Word count: 2473/3000 
Debate article

Title: Training in Multiple Breath Washout testing for respiratory physiotherapists

27

\section{Abstract: 146/200}

Introduction: The development of multiple breath washout (MBW) testing in respiratory disease highlights the need for increased awareness amongst respiratory physiotherapists and a potential opportunity for professional development in the use of an important outcome measure for clinical trials.

Objectives: To rationalise how MBW may be a useful assessment tool for respiratory physiotherapists and to describe a local MBW training and certification programme for physiotherapists.

Results: The respiratory Multi-Disciplinary Team in the Belfast Health and Social Care Trust (BHSCT) identified a need for MBW testing to be available to facilitate clinical research and assessment. A 2 day training programme consisting of pre-reading preparation, self-directed learning, theory presentations, practical demonstrations and hands-on practice was developed and delivered. All participants underwent a certification process.

Conclusion: We have demonstrated the successful training and certification of clinical and research physiotherapists and encourage other respiratory physiotherapists to consider MBW test training. 
Contribution of paper

- This paper highlights the need for increased awareness amongst respiratory physiotherapists and a potential opportunity for professional development in the use of an important outcome measure for clinical trials.

- This paper demonstrates that respiratory physiotherapists can obtain training and certification in MBW testing

\section{Keywords}

Respiratory physiotherapy; multiple breath washout testing; lung clearance index; training; eLearning.

\section{Introduction}

In recent years, there has been a resurgence of interest in multiple breath washout (MBW) testing in respiratory disease. This method has the advantage of improved sensitivity in the detection of early airways disease compared to spirometry and has improved feasibility across a wider age range, requiring only relaxed tidal breathing. Studies in Cystic Fibrosis (CF) have shown that measures of MBW detect early lung disease, relate to measures of spirometry and health related quality of life and are responsive to mucolytic therapies (1-7). Consequently, parameters of MBW have been recommended as outcome measures in clinical trials in CF (8) and have already been used in landmark CF trials $(9,10)$. Research into MBW in other respiratory conditions have also demonstrated that it could be a useful tool to detect disease and measure treatment response (11-14). $\mathrm{FEV}_{1}$ is a key outcome measure in CF and is currently 
89

the only Food and Drug Administration (FDA) approved surrogate outcome measure for use in clinical trials (15). It is also the most commonly used and reported measure of lung function in other lung diseases such as COPD (16). However, FEV 1 has physiological limitations; it primarily reflects the larger airways rather than the more peripheral, smaller airways which make up the majority of the surface area of the lung and where early processes occur (17). Furthermore in $\mathrm{CF}$, the slow rate of decline in $\mathrm{FEV}_{1}$ evident as a result of improved standards of care (18), limit its sensitivity to detect change in clinical status and response to treatment. Spirometry can only be reliably carried out in individuals aged $>6$ years as it requires ability to take instruction and co-operation. There is a clear need for an alternative measurement of lung function. As research has established that MBW is a valid and reliable measure of ventilation distribution which correlates with lung disease severity (8), it has become established as a secondary outcome in clinical trials and may also have a place in regular clinical monitoring in CF. Moreover, MBW could potentially inform physiotherapy assessment and the evaluation of new treatments.

Unlike spirometry, MBW is not part of undergraduate training programmes and there are few training programmes outside specialist research centers. Therefore, in order to facilitate the translation of MBW into clinical care there is a need for effective training. We propose that training respiratory physiotherapists to perform MBW could be advantageous in the management of respiratory patients.

\section{Objectives}

The objectives of this article are to

1. Rationalise how MBW may be a useful assessment tool for respiratory physiotherapists. 
2. Describe a local MBW training and certification programme for physiotherapists.

3. Highlight available MBW training resources.

\section{MBW testing}

In respiratory disease, airway narrowing from mucus obstruction, inflammation and structural airway damage can cause uneven ventilation distribution and the degree of disease severity can be assessed using MBW. Lung Clearance Index (LCI) is the most commonly reported measure of the MBW test and represents the number of functional residual capacity (FRC) volume turnovers required to "washout" the tracer gas during testing. Individuals with uneven ventilation distribution use a greater number of turnovers to washout the tracer gas and therefore will have a higher (more abnormal) LCI. Although MBW tests have been available for many years, research and clinical interest has increased recently due to the availability of more sophisticated and user friendly equipment. The MBW test can be performed either with inhalation of an inert tracer gas such as sulphur hexafluoride $\left(\mathrm{SF}_{6}\right)$ or helium $(\mathrm{He})$, or by using $100 \%$ oxygen $\left(0_{2}\right)$ to wash out resident nitrogen $\left(\mathrm{N}_{2}\right)$. When using $\mathrm{SF}_{6}$ or He, the gas is first washed into the lungs and then washed out. When using $\mathrm{N}_{2}$ washout, $100 \% \mathrm{O}_{2}$ is delivered until $\mathrm{N}_{2}$ is washed out. The European Respiratory Society/American Thoracic Society (ERS/ATS) consensus statement for inert gas washout measurements (19) provides evidence based guidelines on equipment specifications, test performance and analysis of results and is a key reference document for sites planning the set-up and delivery of MBW testing. Some key points about MBW from the inert gas washout measurements consensus statement (19) and an evidence review for LCI (8) are summarized in Table 1. 

detect early lung disease, potentially informing clinical decisions on treatment and management plans earlier in the disease trajectory. It has been shown to detect early lung disease in children and adults and is more sensitive than measures of spirometry (FEV $)_{1}$ in both CF and bronchiectasis (2,5,11). Indices from the MBW test have also been shown to be

- MBW tests assess the efficiency of ventilation distribution (19)

- LCI is the most commonly reported MBW index in current paediatric and adult literature (19)

- LCI is the number of functional residual capacity (FRC) lung volume turnovers required to reduce tracer gas concentration to a fraction of its starting concentration (19)

- End of washout is historically defined as $1 / 40^{\text {th }}$ of the starting tracer gas concentration (19)

- MBW testing requires only tidal breathing and stability of resting lung volumes throughout the washout is critical (19)

- LCI is reported as the mean (SD) of 3 technically acceptable and repeatable washout tests (19)

- In a healthy person, upper limits of normal for LCI between 7.0 - 7.5 have been reported $(2,30)$

- A complete MBW testing session (3 tests) typically lasts between 20 - 40 minutes $(2,31)$

- The minimum clinically important difference in LCI has yet to be defined but treatment effects of 1.0-2.2 lung turnovers have been reported $(3,9,32,33)$

- LCI is dependent on body size and appropriate reference equations are essential for accurate interpretation of results (34)

- Results are specific to equipment and therefore are not comparable across different systems (e.g. system using $\mathrm{SF}_{6}$ vs. system using $\mathrm{N}_{2}$ as tracer gas)

There are key areas where LCI demonstrates potential clinical utility. Firstly, LCI can sensitive to lung disease in asthma (13), COPD (14) and alpha-1-antitrypsin deficiency (20). 

outcomes, which confirms its validity as a useful measure. In CF, LCI has been shown to relate to health related quality of life as measured by a validated questionnaire, and to predict pulmonary exacerbations $(4,21)$. In both CF and bronchiectasis, LCI relates to measures of high resolution computed tomography (HRCT) chest imaging (11). LCI has been shown to be responsive to the disease modulating therapy, ivacaftor, in $\mathrm{CF}$ (9). $\mathrm{LCI}$, but not $\mathrm{FEV}_{1} \%$ predicted, was also responsive to mucoactive therapies including inhaled hypertonic saline (3) and DNase in CF (7). The responsiveness of LCI highlights that it could have a potential role in the assessment of therapies and in the long term monitoring in patients.

A small number of studies have been carried out to investigate the short term effect of airways clearance interventions on LCI in both CF and bronchiectasis. In CF, one study demonstrated a significant reduction (improvement) in LCI following treatment with NonInvasive Ventilation compared to Positive Expiratory Pressure mask in 32 patients with CF (22). Measures of gas mixing efficiency from a single-breath gas washout test also improved significantly after airway clearance in 25 children with CF (23). The majority of studies show no change or a variable change (increase and decrease) in LCI (12,24-26). This highlights that airways clearance techniques cause alterations in gas mixing which are greater than those who do not undergo airway clearance. One theory suggested is that airway clearance may open up previously "blocked off” areas caused by mucus plugging, or relieve areas of atelectasis, opening up poorly ventilated areas, thereby causing a rise (worsening) in LCI. Further studies of the medium to long-term effect of airways clearance techniques on LCI and other MBW test outcomes would be beneficial in informing physiotherapists whether there is a place for MBW 
testing in assessing airways clearance. The challenge with airways clearance trials remains that there is no consensus on the best index to use to measure effect (27).

As MBW testing demonstrates utility across a range of respiratory diseases, both clinical and clinical trial sites are exploring the acquisition of equipment and training in order to embed this outcome measure in trials and to offer this test as part of their assessment. This highlights a development opportunity for respiratory physiotherapists.

\section{The role of respiratory physiotherapists}

Respiratory physiotherapists are directly involved in conducting and interpreting lung function tests and the key role of the physiotherapist in evaluating response to inhaled therapies, airways clearance therapies and physical activity has been highlighted in CF (28). Physiotherapists are ideally placed to build on their existing knowledge and expertise in acquiring the skill of MBW testing, which could potentially be utilized as part of their patient's assessment. Respiratory physiotherapists form an integral part of the multidisciplinary team and are involved in the assessment of patients' respiratory status within the context of outpatient appointments, annual assessments as well as inpatient admissions. MBW testing falls under the Chartered Society of Physiotherapy (CSP) scope of practice of physiotherapy in the UK, defined as "any activity undertaken by an individual physiotherapist that may be situated within the four pillars of physiotherapy practice where the individual is educated, trained and competent to perform that activity” (CSP, 2008) and therefore is covered under professional liability insurance. As MBW testing has its roots in clinical research, conduct of the technique has historically been the remit of the researcher. Implementing research practices into clinical practice is challenging and requires the collaboration and commitment of the academic researchers, clinicians, managers 
and patients. Increasing awareness and knowledge of new assessments, skills required and the wider practical implications are recognised aspects of successful integration of change to practice (29). A key feature of all clinical practice including physiotherapy practice, is the capacity to respond and evolve to changes in healthcare. A focus on providing the training opportunities to support physiotherapists to be competent at embedding new techniques within their clinical practice will facilitate the translation of research into practice. To enable the successful integration into clinical practice, appropriate training in the technical aspects of set up, conducting the test, and interpretation and quality assurance of results is essential (19). Through our experience of delivering a training programme, we have demonstrated how both clinical and research physiotherapists can successfully complete training and certification in this skill for use in research and clinical practice.

\section{Training programme}

The respiratory Multi-Disciplinary Team in Belfast Health and Social Care Trust (BHSCT) identified a need for MBW testing to be available to facilitate clinical research and clinical assessment. In response to this, a 2 day programme was developed and delivered by a Queen's University Belfast $\mathrm{PhD}$ researcher (physiotherapist $\mathrm{KON}$ ) trained in using the modified InnocorTM $^{\mathrm{TM}}$ device (by an external expert in the equipment, Dr Alex Horsley, University of Manchester). The programme consisted of pre-reading preparation, self-directed learning, a presentation on theory, practical demonstrations and practice. Thereafter to be certified, participants completed 10 tests after the 2 day programme which were then assessed for technical validity and repeatability. The trainer was available for trouble shooting on calibration and testing during the certification process. Table 2 details the programme content 
and layout and the certification procedure. Appendix 1 details the programme in full. All content was based on the device Standard Operators Procedure (used with permission) “Multiple breath washout test using modified Innocor ${ }^{\mathrm{TM}}$ device SOP; UK Cystic Fibrosis Gene Therapy Consortium; September 2010, Dr. Nick Bell” and on guidance from external expert Dr Alex Horsley, University of Manchester. A knowledge (6 multiple choice questions) and confidence (Likert visual analogue scales rating setting up the equipment, conducting and interpreting the test) questionnaire was completed by participants before the programme and suggestions for improvement of the programme.

Table 2: Programme content and layout

\section{Preparation:}

Key references and protocols for pre-reading.

\section{Day 1:}

Background to MBW. Overview of references and Standard Operating Procedure. Familiarisation with equipment components, on-screen menus and consumables. Overview and practice of calibrations. Patient preparation for testing.

\section{Day 2:}

Explanation and demonstration of phases of testing: Washin phase, beginning of washout, washout phase. Practice testing with volunteer and quality control of readings. Log keeping, cleaning of equipment and infection control. Accessing and downloading tests.

Certification procedure: 
Trouble shooting on calibration and testing.

Collection of 10 tests.

9/10 technically acceptable tests required for certification.

If $<9 / 10$ tests valid, submission of additional 5 tests.

217

218 The programme was delivered on 2 occasions to a total of 10 participants ( 5 clinical researchers

219 [3 physiotherapists, 1 nurse, 1 clinical physiologist] and 5 clinical physiotherapists) based in

BHSCT. All 10 participants completed the 2 day programme. However 2/10 participants

(clinical physiotherapists) did not complete the certification procedure (no time due to clinical

caseload). The remaining 8 participants successfully completed the certification procedure. Six participants completed the knowledge and confidence assessment before and after the programme and certification (2 participants did not complete the certification and 2 completed the programme before the knowledge and confidence questionnaire was introduced). For these 6 participants, knowledge improved from $61 \%$ at baseline to $100 \%$ post programme. Confidence improved from 3\% at baseline to $76 \%$ post programme; however 2 participants highlighted that they still were not very confident in interpreting MBW results. Suggestions for improvement included the development of eLearning material, the inclusion of content on $\mathrm{N}_{2}$ washout devices and information on the interpretation and analysis of MBW results.

Experience from this programme demonstrates how both clinical and research physiotherapists can successfully complete a training and certification programme in MBW testing. As 2 clinical staff members were unable to complete certification due to time constraints it highlights that agreement and ongoing support from management is required to ring fence time to organise and complete certification readings. 
237 For those wishing to pursue training in MBW testing, the ERS/ATS inert gas washout consensus statement provides a comprehensive outline on all aspects of equipment specifications, test performance and analysis (19). As MBW testing involves practical and technical skills, face-to-face training for “hands-on” experience is considered optimal. During the equipment installation process manufacturers usually provide training according to their standard operating procedure. Additional training is required to obtain certification to a research quality standard and there are UK sites who provide training, certification and an overreading service (quality checking and final result verification of MBW data) as well as a point of contact for re-fresher training and troubleshooting. (Royal Brompton and Harefield Hospital, London and BHSCT).

MBW testing is a developing area and is technically challenging to perform. Therefore, regular practice with quality control checks is essential to ensure that confidence and competence with use of the equipment is maintained. Re-fresher training is important if time has elapsed since original training or last use. As MBW is primarily a research tool at present, 251 it is possible that the operator may become deskilled if using the method infrequently or only during a specific clinical trial. eLearning tools are one method that reinforce face-to-face learning and support re-fresher training remotely. Some eLearning resources have been developed by commercial companies using MBW testing, however access is restricted to sites participating in the clinical trial. An eLearning tool developed at Queen’s University Belfast (www.MBWtraining.com), is open access and provides comprehensive information on MBW testing using a variety of learning mediums including slideshow presentations, animations and a step by step library of videos demonstrating set-up and testing. The tool also includes a self- 
assessment component, a social networking interface and teaching team contact details for ongoing support. In addition to reinforcement of face-to-face learning, this eLearning tool aims to facilitate ongoing and re-fresher training and act as a point of contact for troubleshooting and quality assurance issues. This blended learning approach (face-to-face programme supported by eLearning) aims to provide an effective and accessible form of MBW training to sites.

\section{Conclusions}

MBW to measure LCI is emerging as a promising outcome measure with potential for integration into routine clinical management of patients with CF and growing potential for use in bronchiectasis, asthma and COPD. In order for integration into clinical practice to be successful, training of the appropriate personnel in the technical aspects of set up, conducting the test, interpretation and quality assurance of results is essential. We propose that respiratory physiotherapists are ideally placed to undergo such training and become qualified to perform the MBW technique in response to expansions in service delivery. We have demonstrated the successful training and certification of clinical and research physiotherapists and encourage other respiratory physiotherapists to explore the area of MBW test training.

277 Ethical approval: n/a

278 Funding: The training programme described in this article was carried out as part of a USIreland Partnership Grant funded by the Health and Social Care Research and Development 280 Division, Public Health Agency, Northern Ireland and the Medical Research Council. The 
282 from the Health \& Social Care Research \& Development Division of the Public Health Agency

283 (HSC R\&D Division).

284 Conflict of interest: The authors have no conflicts of interest to disclose.

285

286

287

288

289

290

291

292

293

294

295

296

297

298 
300 (1) Gustafsson PM, Aurora P, Lindblad A. Evaluation of ventilation maldistribution as an 301 early indicator of lung disease in children with cystic fibrosis. European Respiratory Journal 2003 Dec 2003;22(6):972-979.

303 (2) Horsley AR, Gustafsson PM, Macleod KA, Saunders C, Greening AP, Porteous DJ, et al. 304 Lung clearance index is a sensitive, repeatable and practical measure of airways disease in 305 adults with cystic fibrosis. Thorax 2008 Feb;63(2):135-140.

306 (3) Amin R, Subbarao P, Jabar A, Balkovec S, Jensen R, Kerrigan S, et al. Hypertonic saline 307 improves the LCI in paediatric patients with CF with normal lung function. Thorax 2010 308 May;65(5):379-383.

309 (4) Vermeulen F, Proesmans M, Boon M, Havermans T, De Boeck K. Lung clearance index 310 predicts pulmonary exacerbations in young patients with cystic fibrosis. Thorax 2014 311 Jan;69(1):39-45.

(5) O'Neill K, Tunney MM, Johnston E, Rowan S, Downey DG, Rendall J, et al. Lung clearance index in adults and children with cystic fibrosis. Chest 2016;150(6):1323-1332. doi:10.1016/j.chest.2016.06.029.

(6) Hannon D, Bradley JM, Bradbury I, Bell N, Elborn JS, O'Neill K. Shortened Lung Clearance Index is a repeatable and sensitive test in children and adults with cystic fibrosis. BMJ Open Respiratory Research 2014 July 01;1(1).

320 (7) Amin R, Subbarao P, Lou W, Jabar A, Balkovec S, Jensen R, et al. The effect of dornase 321 alfa on ventilation inhomogeneity in patients with cystic fibrosis. Eur Respir J 2011

322 Apr;37(4):806-812.

(8) Kent L, Reix P, Innes JA, Zielen S, Le Bourgeois M, Braggion C, et al. Lung clearance index: Evidence for use in clinical trials in cystic fibrosis. J Cyst Fibros 2014 Mar;13(2):123138.

(9) Davies J, Sheridan H, Bell N, Cunningham S, Davis SD, Elborn JS, et al. Assessment of clinical response to ivacaftor with lung clearance index in cystic fibrosis patients with a

328 G551D-CFTR mutation and preserved spirometry: a randomised controlled trial. The Lancet 329 Respiratory Medicine 2013 10;1(8):630-638.

330 (10) Kane M, Gonska T, Jensen R, Avolio J, Klingel M, Stanojevic S, et al. Lung clearance 
(11) Rowan SA, Bradley JM, Bradbury I, Lawson J, Lynch T, Gustafsson P, et al. Lung Clearance Index Is a Repeatable and Sensitive Indicator of Radiological Changes in Bronchiectasis. Am J Respir Crit Care Med 2014 03/01; 2014/03;189(5):586-592.

(12) Grillo L, Irving S, Hansell DM, Nair A, Annan B, Ward S, et al. The reproducibility and responsiveness of the lung clearance index in bronchiectasis. European Respiratory Journal 2015 European Respiratory Society;46(6):1645-1653.

(13) Zwitserloot A, Fuchs SI, Muller C, Bisdorf K, Gappa M. Clinical application of inert gas Multiple Breath Washout in children and adolescents with asthma. Respir Med 2014 Sep;108(9):1254-1259.

(14) Husemann K, Berg N, Engel J, Port J, Joppek C, Tao Z, et al. Double tracer gas singlebreath washout: reproducibility in healthy subjects and COPD. Eur Respir J 2014 Nov;44(5):1210-1222.

(15) Kerem E, Reisman J, Corey M, Canny GJ, Levison H. Prediction of mortality in patients with cystic fibrosis. N Engl J Med 1992 Apr 30;326(18):1187-1191.

(16) Rabe KF, Hurd S, Anzueto A, Barnes PJ, Buist SA, Calverley P, et al. Global Strategy for the Diagnosis, Management, and Prevention of Chronic Obstructive Pulmonary Disease. Am J Respir Crit Care Med 2007 09/15; 2016/05;176(6):532-555.

(17) Tiddens HA, Donaldson SH, Rosenfeld M, Pare PD. Cystic fibrosis lung disease starts in the small airways: can we treat it more effectively? Pediatr Pulmonol 2010 Feb;45(2):107117.

(18) Registry Steering Committee. UK CF Registry Report. 2012.

(19) Robinson PD, Latzin P, Verbanck S, Hall GL, Horsley A, Gappa M, et al. Consensus statement for inert gas washout measurement using multiple- and single- breath tests. European Respiratory Journal 2013 March 01;41(3):507-522.

(20) Fuchs SI, Schwerk N, Pittschieler K, Ahrens F, Baden W, Bals R, et al. Lung clearance index for monitoring early lung disease in alpha-1-antitrypsin deficiency. Respir Med 2016/06;116:93-99.

(21) O'Neill K, Johnston E, Tunney M, Elborn JS, Bradley JM. WS7.3 Relationships between lung clearance index (LCI), patient reported symptoms and health related quality of life (HRQoL) in CF. Journal of Cystic Fibrosis 2012 6;11, Supplement 1(0):S14.

(22) Rodriguez Hortal MC, Nygren-Bonnier M, Hjelte L. Non-invasive Ventilation as Airway Clearance Technique in Cystic Fibrosis. Physiother Res Int 2016 Feb 29. doi: 10.1002/pri.1667. [Epub ahead of print] 
(23) Abbas C, Singer F, Yammine S, Casaulta C, Latzin P. Treatment response of airway clearance assessed by single-breath washout in children with cystic fibrosis. J Cyst Fibros 2013 Dec;12(6):567-574.

(24) Fuchs SI, Toussaint S, Edlhaimb B, Ballmann M, Gappa M. Short-term effect of physiotherapy on variability of the lung clearance index in children with cystic fibrosis. Pediatr Pulmonol 2010 Mar;45(3):301-306.

(25) Pfleger A, Steinbacher M, Schwantzer G, Weinhandl E, Wagner M, Eber E. Short-term effects of physiotherapy on ventilation inhomogeneity in cystic fibrosis patients with a wide range of lung disease severity. J Cyst Fibros 2015 Sep;14(5):627-631.

(26) O'Neill K, Moran F, Tunney MM, Elborn JS, Bradbury I, Downey DG, et al. Timing of hypertonic saline and airway clearance techniques in adults with cystic fibrosis during pulmonary exacerbation: pilot data from a randomised crossover study. BMJ Open Resp Res 2017 British Thoracic Society;4(1).

(27) Main E. Airway clearance research in CF: the 'perfect storm' of strong preference and effortful participation in long-term, non-blinded studies. Thorax 2013 Aug;68(8):701-702.

(28) Flume PA, Aitken ML, Bilton D, Agent P, Charlton B, Forster E, et al. Optimising inhaled mannitol for cystic fibrosis in an adult population. Breathe (Sheff) 2015 Mar;11(1):39-48.

(29) National Institute for Healthcare and Excellence (NICE). How to change practice: understand, identify and overcome barriers to change. 2013.

(30) Fuchs SI, Eder J, Ellemunter H, Gappa M. Lung clearance index: normal values, repeatability, and reproducibility in healthy children and adolescents. Pediatr Pulmonol 2009 Dec;44(12):1180-1185.

(31) Singer F, Kieninger E, Abbas C, Yammine S, Fuchs O, Proietti E, et al. Practicability of nitrogen multiple-breath washout measurements in a pediatric cystic fibrosis outpatient setting. Pediatr Pulmonol 2013 Aug;48(8):739-746.

(32) Subbarao P, Stanojevic S, Brown M, Jensen R, Rosenfeld M, Davis S, et al. Lung clearance index as an outcome measure for clinical trials in young children with cystic fibrosis. A pilot study using inhaled hypertonic saline. Am J Respir Crit Care Med 2013 Aug 15;188(4):456-460.

(33) Sonneveld N, Stanojevic S, Amin R, Aurora P, Davies J, Elborn JS, et al. Lung clearance index in cystic fibrosis subjects treated for pulmonary exacerbations. Eur Respir J 2015 Oct;46(4):1055-1064. 

dependence of lung clearance index and functional residual capacity. Eur Respir J 2013

401 Jun;41(6):1371-1377.

402 


\section{Appendix 1: Training Programme: Multiple Breath Washout Test using Modified Innocor $^{\mathrm{TM}}$ device: Queen’s University Belfast \& Belfast Health and Social Care Trust}

\section{$\underline{\text { PROGRAMME }}$}

Multiple Breath Washout (MBW) Test using Modified Innocor ${ }^{\mathrm{TM}}$ device: Queen’s University Belfast \& Belfast Health and Social Care Trust

Author: Katherine O’Neill, Prof. Judy Bradley, Prof. Stuart Elborn.

\section{INSTRUCTIONAL GOALS}

At the end of this course, you will:

- Understand the principals underpinning MBW testing.

- Be able to independently prepare the InnocorTM device and the testing room for procedure.

- Be able to independently set up device and perform all calibration procedures as per SOP

- Be able to maintain the set up to standard as per infection control guidelines in the SOP.

- Know how to complete and maintain the Innocor ${ }^{\mathrm{TM}}$ Usage log and the MBW Procedure and Analysis Washout Sheets.

- Know how to adequately explain and prepare patient for procedure.

- Be able to successfully conduct MBW test on adults as per SOP.

- Be able to recognize technically inadequate tests that may warrant an additional test.

- Be able to export the test tracings from the Innocor ${ }^{\mathrm{TM}}$ device in preparation for analysis. 
NEEDS AND RESOURCES

\section{Required Background}

To successfully complete this course, you must;

- $\quad$ Read the key references

Robinson, P.D., Goldman, M.D. \& Gustafsson, P.M. 2009, "Inert gas washout: theoretical background and clinical utility in respiratory disease", Respiration, vol. 78, no. 3, pp. 339355.

Horsley, A. 2009, "Lung clearance index in the assessment of airways disease", Respiratory medicine, vol. 103, no. 6, pp. 793-799

- $\quad$ Read the SOP

Multiple breath washout test using modified InnocorTM device SOP; Nick Bell; Clinical Research Fellow; UK Cystic Fibrosis Gene Therapy Consortium; 20th September 2010.

\section{Required Equipment}

To commence and successfully complete this course, you will need

- $\quad$ Innocor $^{\mathrm{TM}}$ in place with adaptations made as per SOP (see page appendix C SOP)

- Supply of SF6 gas (NB: Wall bracket or cylinder trolley for size L cylinder required; flow head/regulator for size L cylinder required (ordered through BOC part number 850820) (see page 5 SOP) 
- Room set up for procedure (see page 5 SOP)

- Flow past circuit and patient interface consumables in stock (see page 19 SOP)

\section{Required Materials}

To successfully complete this course, you will need;

- Multiple breath washout test using modified Innocor ${ }^{\mathrm{TM}}$ device SOP; Nick Bell; Clinical Research Fellow; UK Cystic Fibrosis Gene Therapy Consortium; 20th September 2010.

- MBW Procedure and Analysis Washout Sheets

- Multiple Breath Washout Test using the Modified Innocor ${ }^{\mathrm{TM}}$ device ; LCI operator Qualification Assessment Form; Oct 2011

- Innocor $^{\mathrm{TM}}$ Instructions for Use Manual 


\section{TRAINING ITEMS}

1. Overview of references and SOP.

2. Checklist of all equipment and consumables in place

3. Set up room, equipment and patient interface

4. Familiarisation with equipment
a) Innocor $^{\mathrm{TM}}$
b) Innocor $^{\mathrm{TM}}$ menus
c) Patient interface
d) Flow past circuit
e) Gas cylinder
f) Room set up

5. Practice with set up and calibration
a) Flow meter linearization
b) Flow meter calibration
c) Flow gas delay calibration

6. Preparing and explaining procedure to patients

7. Concepts of washin; disconnection and washout (as per SOP).

8. $\quad$ Observe a test $*$ Volunteer needed*

9. Supervised practice with patients / volunteers *Volunteer(s) needed* 


a) Including keeping the log and note keeping during the test.
b) Troubleshooting: Awareness of reasons for invalid tests (technician related
and patient related) and how to avoid.
10. Infection control procedures
a) Patient interface
b) Room
11. Accessing and downloading tracings; sending tracings to analyzer.
12. Information obtained post analysis.
If $<9 / 10$ tests valid, submission of additional 5 tests
Trouble shooting on calibration and testing.
Collection of 10 tests.


Appendix 2: Knowledge and Confidence Assessment Questionnaire_ Multiple Breath Washout Test using Modified Innocor ${ }^{\mathrm{TM}}$ device_Queen’s University Belfast \& Belfast Health and Social Care Trust_Katherine O’Neill_March 2013

$\underline{\text { Knowledge assessment questionnaire }}$

Multiple choice questions- Please choose one 


\section{LCI is derived from}
a) Single breath washout test
b) Multiple breath washout test
c) Body plethysmography test
d) Diffusion capacity test

\section{LCI is a measure of}
a) Airflow
b) Perfusion
c) Inflammation
d) Gas mixing efficiency

3. The upper limit of normal for LCI is
a) 10
b) 5.5
c) 7.5
d) 15.5

\section{LCI is calculated as}
a) The number of lung turnovers required to washout a tracer gas
b) The concentration of tracer gas at functional residual capacity 
c) The mean concentration of $\mathrm{CO}_{2}$ at end tidal volume

d) The number of lung regions ventilated

\section{LCI is a measure most sensitive to}
a) Large airways dysfunction
b) Small airways dysfunction
c) $\mathrm{Sp}_{2}$ levels
d) Airways inflammation

6. LCI is a measure which is most informative in
a) Patients with advanced disease
b) Patients awaiting transplant
c) Healthy individuals
d) Children and patients with mild disease 
Please answer the following questions which relate to your confidence in MBW procedure to obtain LCI

Rate your confidence performing calibration procedures for MBW testing before starting the training programme

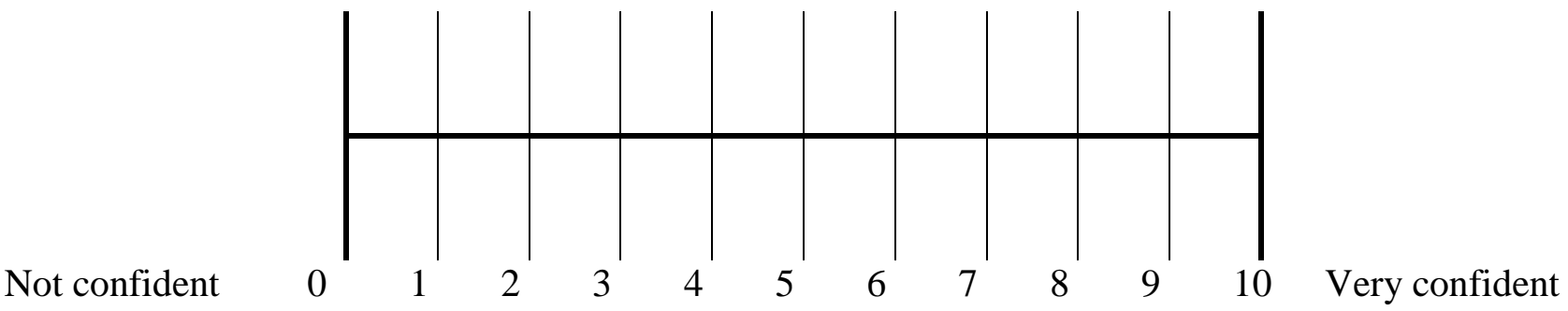

Rate your confidence performing calibration procedures for MBW testing on completion of the training programme

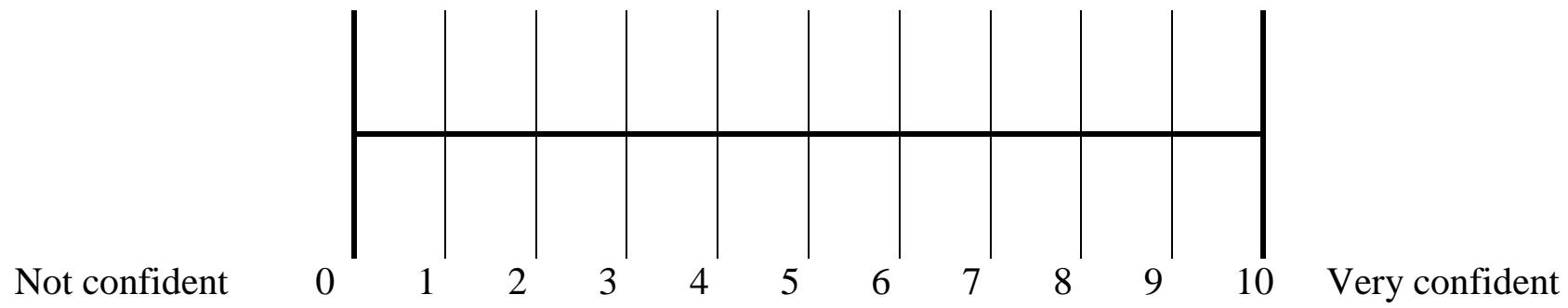


Rate your confidence using equipment to perform MBW test before starting the training programme

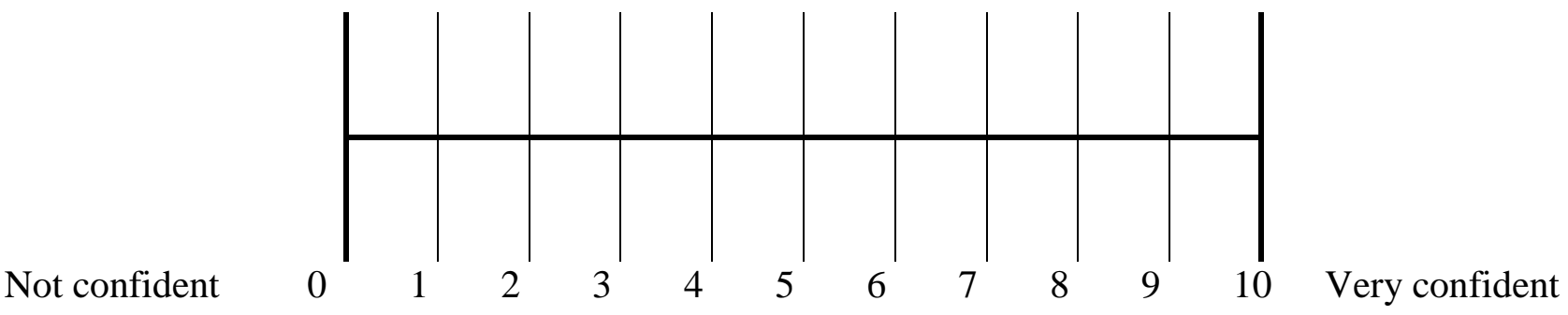

Rate your confidence using equipment to perform MBW test on completion of the training programme

Not confident

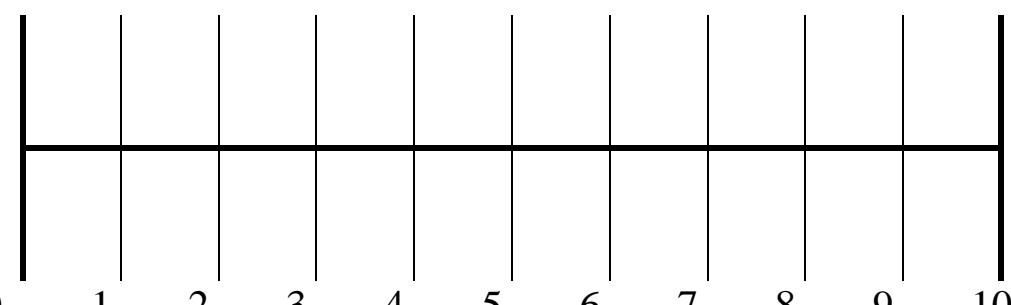

Very confident

Rate your confidence on interpreting the LCI result from the results sheet before starting the training programme

Not confident

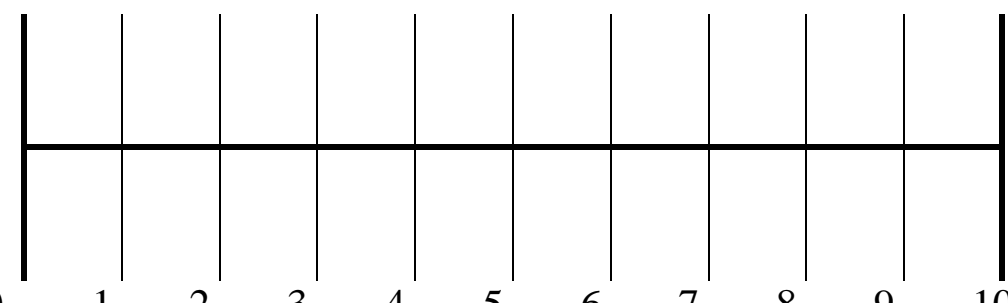

Very confident 
Rate your confidence interpreting the LCI result from the results sheet on completion of the training programme

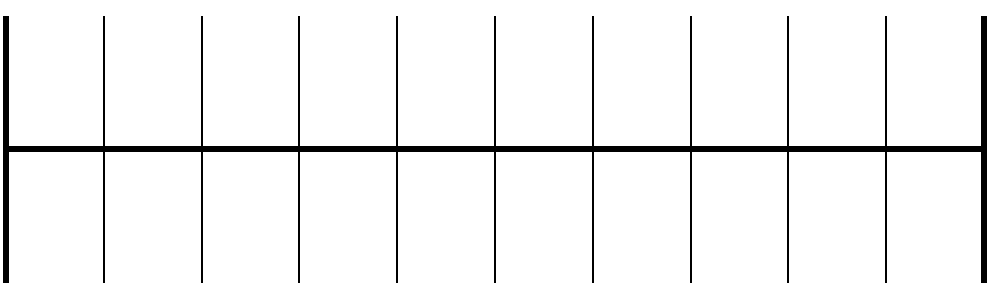

$\begin{array}{lllllllllllll}\text { Not confident } & 0 & 1 & 2 & 3 & 4 & 5 & 6 & 7 & 8 & 9 & 10 & \text { Very confident }\end{array}$

Rate your confidence on maintenance of the MBW equipment before starting the training programme

Not confident

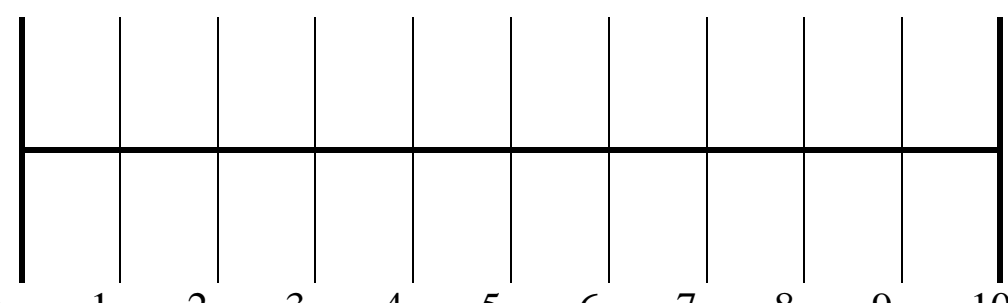

Very confident

Rate your confidence maintenance of the MBW equipment on completion of the training programme

Not confident

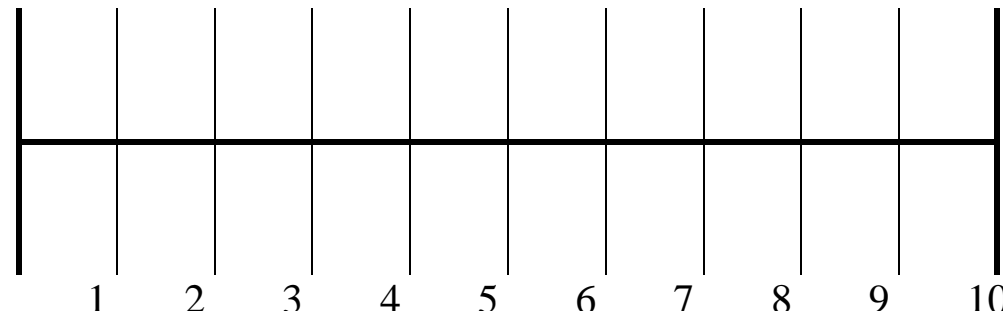

Very confident 